\title{
An Empirical Analysis of Denmark's Energy Economy and Environment and Its Sustainable Development Policy
}

\author{
Chun-juan Wang ${ }^{1,2,5}$, Xiao $\mathrm{Han}^{3}$, Su Xin ${ }^{2}$, Da-hai Liu ${ }^{1,5}$, Meng Xu ${ }^{1}$, Jian-qiu Ma ${ }^{4} \&$ Ying Yu ${ }^{1}$ \\ ${ }^{1}$ First Institute of Oceanography, Ministry of Natural Resource, Qingdao, China \\ ${ }^{2}$ China University of Geosciences (Beijing), Beijing, China \\ ${ }^{3}$ Shandong University, Jinan, China \\ ${ }^{4}$ Ocean University of China, Qingdao, China \\ ${ }^{5}$ Laboratory for Marine Geology, Qingdao National Laboratory for Marine Science and Technology, Qingdao, \\ China
}

Correspondence: Chun-juan Wang, First Institute of Oceanography, Ministry of Natural Resource, Qingdao, China.E-mail: cjw@fio.org.cn

Received: February 11, 2019

Accepted: March 11, 2019

Online Published: March 30, 2019

doi:10.5539/jsd.v12n2p29

URL: https://doi.org/10.5539/jsd.v12n2p29

\begin{abstract}
As a model for energy transition to low-carbon economy, Denmark is of great importance for studying internal relationships between economic growth, both energy consumption and production, and Carbon emissions. Based on Denmark's data for the total consumption of petroleum oil and gas resources, total production of oil and gas resources, gross domestic product(constant 2010 US\$) and $\mathrm{CO}_{2}$ emissions over the time span 1984-2016, Johansen test shows that there is no cointegration relationship between $\mathrm{CO}_{2}$ emissions and oil and gas consumption, and the autoregressive distributed lag (ARDL) boundary cointegration test shows that there is no cointegration relationship between $\mathrm{CO}_{2}$ emissions and economic growth. Nevertheless, ARDL boundary cointegration test is used to confirm the existence of cointegration between economic growth and both the energy production and consumption. We then establish an error correction model to analyze the short-term relationship between these two cointegrated metrics. The Granger causality test indicates that there is one-way causality between economic growth and energy consumption and energy production; in particular, economic changes help explain changes of energy consumption and production in the future. Finally, the empirical analysis results are further discussed with consideration of Denmark's energy policies and the current state of its energy economy. The results of the present study can help the other countries in the design of energy development, the clean and low carbon energy transition policies for sustainable and long-term economic development.
\end{abstract}

Keywords: economic growth, energy consumption, energy production, carbon emissions, cointegration theory, error correction model, Denmark

\section{Introduction}

In the early 1970s, Denmark had a single energy structure with a self-sufficiency rate of less than $2 \%$. As a major source of Denmark's energy consumption, petroleum relied entirely on imports and accounted for 93\% of Denmark's energy consumption. The oil crisis of 1973 prompted Denmark to actively adopt an energy tax policy. Starting in 1977, Denmark began to tax oil, coal, natural gas and other fossil energy sources, thereby reducing domestic energy demand; meanwhile, Denmark also focused on developing domestic North Sea oil and gas resources, improving oil and gas self-sufficiency rates, encouraging the increase in coal imports and use, and striving to diversify energy supply. Since the 1990s, the production of oil and gas in the North Sea has been reduced, and environmental problems such as global warming have become more serious. Denmark has proposed to end its reliance on fossil fuels by vigorously developing onshore and offshore wind power and increasing the use of biomass energy. In 2005, the proportion of oil consumption in Denmark's total energy consumption was $42 \%$ and was nearly 10 million tons less than in the early 1970 s, while the proportions of natural gas, coal, and renewable energy increased from less than $1 \%$ to $22.76 \%, 19.53 \%$, and $15.35 \%$, respectively. The proportion of renewable energy consumption to total energy consumption increased year by year, from approximately $6 \%$ in 1990 to nearly $13 \%$ in 2003 . The proportion of power generated from renewable 
energy to total power generation was also on the rise from less than $5 \%$ in 1994 to $23 \%$ in 2003 . Currently, Denmark is a net exporter of petroleum and natural gas. Since the renewable energy development technology is at the initial stage of development, natural gas will become an important partner in renewable energy and currently accounts for $26 \%$ of primary energy.

Denmark is an affluent country with an open economy that depends on foreign trade. Denmark's total economic output accounts for $2.1 \%$ of the gross domestic product (GDP) of the European Union (EU), but its population only accounts for $1.4 \%$ of the entire EU population. Its per capita GDP ranks fourth in the world. Since 1980, Denmark has launched two energy revolutions. Its wind power industry and wind turbine manufacturing industry have reached a certain scale and are very competitive. Its wind power equipment and products account for $40 \%$ of the world market share. The output value of clean energy technology is 9.4 billion US dollars, accounting for $3.1 \%$ of Denmark's GDP and ranking first in the world. Denmark's cumulative economic growth has exceeded $70 \%$ since the 1980 s.

In terms of Denmark's energy structure and the development of its economic industry, it is not difficult to see that petroleum and natural gas are important indicators for the transition of Denmark's energy. Studying the relationship between supply and demand of Denmark's energy resources and economic growth bears great significance in explaining its existing energy policies and developing new ones. Judging the interrelationship between energy production, consumption and economic growth requires not only certain economic theoretical basis, but also empirical analysis based on orderly data. It is not only from the perspective of time trend or trend change to judge the interrelationship, but also requires to combine mathematical statistics methods to judge rationality based on reliable data. On the basis of analyzing and judging the relationship between energy consumption and production data and economic growth data, this paper analyzes the impact of Denmark's energy policy on its economy in the corresponding period and the role of the relationship between economic development and energy use in promoting or inhibiting its energy policy-making, and then provide effective reference basis for its energy policy.

In recent years, many scholars in China and abroad have used the cointegration and error correction model to analyze the relationships between economic growth and both energy consumption, but there are few studies on the relationship between energy production, economic growth and carbon emissions, Different research methods and sample data from different countries in different periods may also result in different conclusions. Based on the autoregressive distributed lag (ARDL) boundary cointegration test and the Granger causality test, this paper studies the relationships between economic growth and both the consumption and production of energy resources. This paper analyzes the impact of Danish energy policy on energy production and consumption in order to provide a mathematical and economic basis for future energy policy formulation.

\section{Data and Methodology}

\subsection{Variables and Data}

In order to gain valuable insights into the long-run and short-run dynamics as well as the causal relationships between energy consumption and production, economic growth and carbon emissions in Denmark, based on the research purpose and in consideration of the characteristics of the research object, we defines the following four variables:

(1) Energy consumption indicator: As petroleum and natural gas account for a large proportion of Denmark's energy structure, the total consumption of Denmark's petroleum and natural gas (in tons of oil equivalent) is used to reflect the energy consumption, and the variable is denoted as consumption.

(2) Energy production indicator: The total amount of Denmark's petroleum and natural gas production (in tons of oil equivalent) is used to reflect the energy production, and the variable is denoted as production.

(3) Economic growth indicator: Denmark's GDP is used to reflect its economic growth. To eliminate the impact of inflation, we uses the "GDP (constant 2010 US\$)" data provided by the World Bank to measure its economic growth. The variable is denoted as GDP.

(4) Environmental impact indicators: Denmark's $\mathrm{CO}_{2}$ emissions to reflect the Danish environmental carbon emissions, data for the total amount of data, the unit is 1000 tons, the variable is recorded as $\mathrm{CO}_{2}$.

To eliminate the influence of heteroscedasticity, total oil and gas consumption, total oil and gas production, GDP, and $\mathrm{CO}_{2}$ data are taken logarithm, and the resulting variables are denoted as Inconsumption, Inproduction, $\ln G D P$, and $\ln \mathrm{CO}_{2}$ respectively.

Given data availability and the sample size requirement for the research method, 1984-2016 is selected as the 
sample period, with 33 samples acquired by using the data for each year as one sample. It should be noted that the $\mathrm{CO}_{2}$ emissions data are missing from 2015 to 2016, and the relevant research sample period is from 1984 to 2014. GDP and $\mathrm{CO}_{2}$ emissions data are obtained from the World Bank database, and energy production and consumption data are obtained from the BP database.

\subsection{Descriptive Statistics of Energy Production, Consumption, GDP and $\mathrm{CO}_{2}$ Emissions}

The trends of energy production and consumption and GDP and $\mathrm{CO}_{2}$ of Denmark's from 1984 to 2016 are shown in Fig. 1 which we draw by Matlab based on the data described above, which shows that the GDP series in the sample period generally indicates an increasing trend. In 1994, the economic growth rate accelerated. From 2008 to 2009, the economic growth turned negative due to the financial crisis. From 2010 to 2011, the economy maintained slight but steady growth. In 2014, the economy extended its recovery and continued to grow. The early 1990s witnessed the turning point of the supply and demand ratio of Denmark's energy resources. Prior to this period, the total production of energy resources was less than the total consumption. After this period, the total energy production was greater than the total energy consumption; the consumption of energy resources in the sample period follows an "inverted V" pattern, and the series trend was stable from the mid-1980s to the early 1990s. After that period, the consumption of energy resources decreased, but natural gas consumption increased, with the series showing an upward trend. The environmental crisis of the mid-1990s prompted Denmark to further improve its energy structure, with the series showing a downward trend. The production series and the consumption series are generally similar; however, the production series shows greater fluctuations, with a significant increase before 2005 and a significant decline after 2005. The $\mathrm{CO}_{2}$ emissions series showed a general downward trend, and it was in a state of steady fluctuation before the mid-1990s, after which the series showed a significant downward trend.
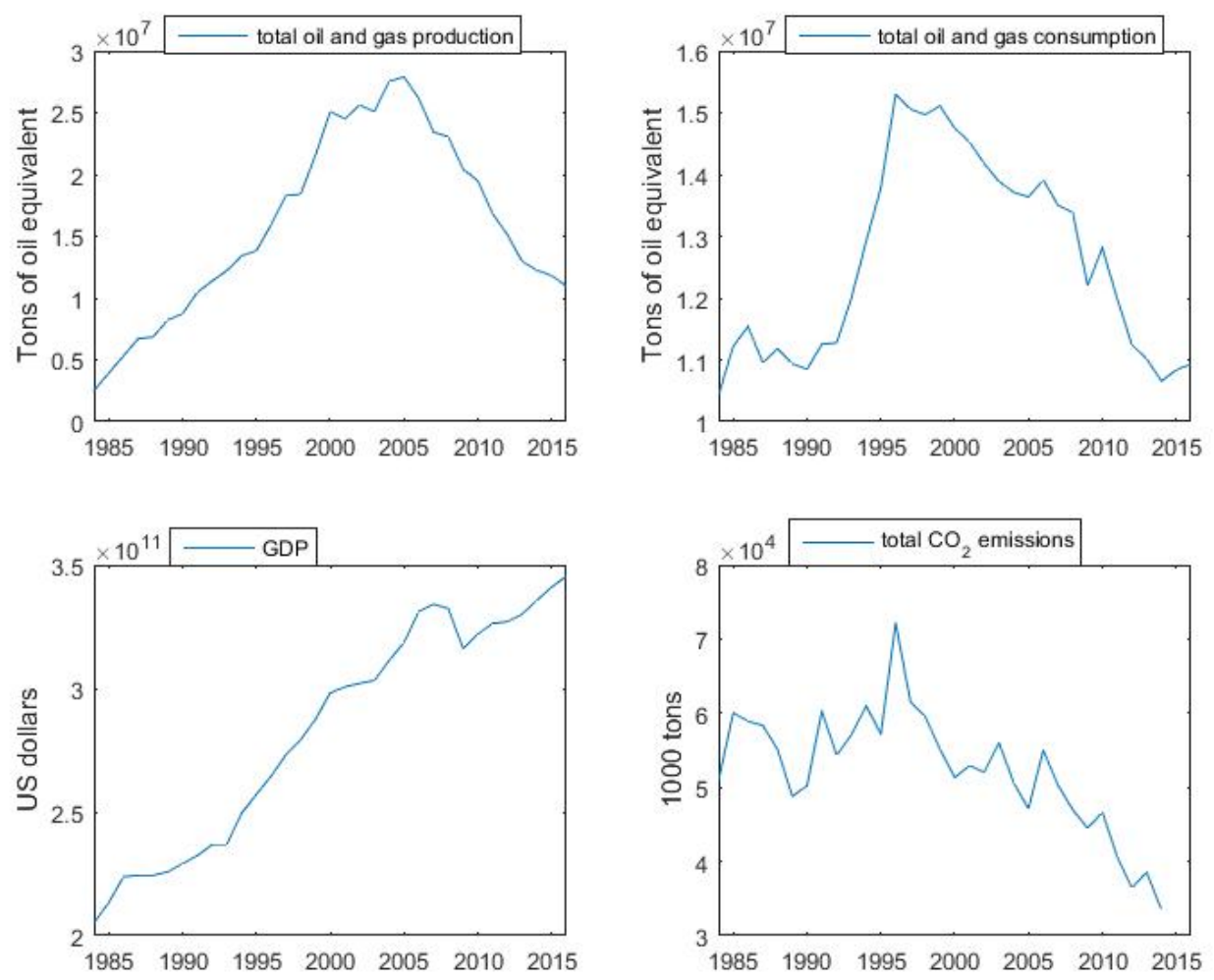

Figure 1. Time series of GDP, $\mathrm{CO}_{2}$ emissions and production and consumption of oil and gas

\subsection{The Cointegration Methodology}

The cointegration theory primarily studies the long-term equilibrium relationship of two (or more) non-stationary time series. The proposal of this theory is of great significance for studying the relationships between non-stationary economic variables using econometric models. If a certain linear combination (cointegration 
vector) of several non-stationary time series reduces the order of integration of the combined time series, then the series are said to be cointegrated. Determining cointegration relationships is an effective method to avoid pseudo-regression, whose variables will not return to equilibrium once they deviate from equilibrium. In contrast, cointegration variables may deviate from equilibrium in a given period, but they could return to equilibrium after a certain period of time. The error correction model is used to describe how the variables return to equilibrium.

Granger's representation theorem describes the relationship between cointegration and error correction models; that is, an error correction model can be established between non-stationary variables with cointegration relations. Studying the causal relationship between energy and economy is of great importance in policymaking. The Granger causality test is a commonly used statistical test for analyzing the causal relationship between variables under the premise of the existence of a cointegration relationship between the variables. The basic principle is thus: if the past information of variables $\mathrm{X}$ and $\mathrm{Y}$ provides a better prediction effect on variable $\mathrm{Y}$ than the past information of variable $\mathrm{Y}$ alone, then variable $\mathrm{X}$ is said to help explain the future change in variable $\mathrm{Y}$, and variable $\mathrm{X}$ Granger-causes variable $\mathrm{Y}$.

\section{Empirical Analysis}

\subsection{Stationarity Test}

Series of the same order of integration may be cointegrated. Therefore, before performing the cointegration test, it is necessary to examine the order of integration of the series, that is, to determine the number of orders of difference needed for a stationary series. This paper used an augmented Dickey-Fuller (ADF) unit root test to perform a stationarity test on the variables inconsumption, lnproduction, $\ln G D P, \ln \mathrm{CO}_{2}$ and as well as their first-order difference series. All regression processes in this paper are implemented using the Eviews 10 (Quantitative Micro Software). The test results in Table1 show that at the 1\% significance level, the four series are not stable, but the first-order difference series are stable. Therefore, the four series are all series of first-order integration(which mean it becomes stationaryafter one difference) and the cointegration relationship between variables can be further examined.

Table 1. ADF unit root test

\begin{tabular}{|c|c|c|c|c|}
\hline $\begin{array}{c}\text { Logarithmic } \\
\text { series/difference } \\
\text { term }\end{array}$ & $\begin{array}{l}\text { Test } \\
\text { form }\end{array}$ & $P$ value & Conclusion & Notes \\
\hline \multirow[t]{2}{*}{$\ln G D P$} & $(C, 0,0)$ & 0.3323 & non-stationary & 1.In the test form, $\mathrm{C}$ in the \\
\hline & $/(C, 0,0)$ & $/ 0.3361$ & / non-stationary & parentheses indicates that \\
\hline \multirow[t]{2}{*}{$\triangle \operatorname{lnGDP}$} & $(C, 0,0)$ & 0.0024 & stationary*** & there is a constant term, $T$ \\
\hline & $/(C, 0,0)$ & /0.0038 & / stationary*** & indicates that there is a trend \\
\hline \multirow[t]{2}{*}{ Inconsumption } & $(C, T, 0)$ & 0.9440 & non-stationary & term, 0 indicates no constant \\
\hline & $/(C, T, 0)$ & /0.9896 & / non-stationary & term or trend term, and the \\
\hline \multirow[t]{2}{*}{$\Delta$ Inconsumption } & $(0,0,0)$ & 0.000 & stationary $* * *$ & last digit indicates the lag \\
\hline & $/(\mathrm{C}, \mathrm{T}, 0)$ & /0.0026 & / stationary $* * *$ & order, which is determined by \\
\hline Inproduction & $(C, T, 0)$ & 0.5522 & non-stationary & the Akaike information \\
\hline$\Delta / n p r o d u c t i o n$ & $(C, T, 0)$ & 0.0003 & stationary $* * *$ & criterion (AIC). \\
\hline $\operatorname{lnCO}{ }_{2}$ & $(C, T, 1)$ & 0.8946 & non-stationary & 2. ${ }^{* * *}$ indicates a $1 \%$ level of \\
\hline$\Delta / n C O_{2}$ & $(C, T, 0)$ & 0.0000 & stationary $* * *$ & significance. \\
\hline
\end{tabular}

\subsection{Cointegration Test}

\subsubsection{Johansen Cointegration Test}

The Johansen test is used to determine whether the two variables of $\ln \mathrm{CO}_{2}$ and lnconsumption are cointegration. A vector regression (VAR) model is established by using the horizontal values of Eviews 10 pairs of variables $\ln \mathrm{CO}_{2}$ and lnconsumption, and setting the lag order not more than 4 and the optimal lag order as 1 . Based on this above basis, the results of Johansen test show that at the 5\% significance level, the results of trace test and 
maximum eigenvalue test are consistent, that is, the original hypothesis is accepted. There is no cointegration relationship between $\mathrm{CO}_{2}$ emissions and oil and gas consumption in Denmark.

\subsubsection{ARDL Boundary Cointegration Test}

The ARDL boundary cointegration test proposed by Pesaran, Shin \& Smith (PSS) is robust when applied to small samples. This method requires that the order of integration for the study series does not exceed 1 . Let be a dependent variable and be independent variables; the general can then be expressed as follows:

$$
y_{t}=a_{0}+a_{1} t+\sum_{i=1}^{p} \psi_{i} y_{t-i}+\sum_{j=1}^{k} \sum_{l_{j}=0}^{q_{j}} \beta_{j, l_{j}} x_{j, t-l_{j}}+\varepsilon_{t}
$$

where is a white noise process, $t$ represents a trend term, $p$ is the lag order of the dependent variable, and is the lag order of the $\mathrm{j}^{\text {th }}$ independent variable. In Formula (1), the determination of lag order is usually based on setting the maximum lag order first, then selecting the optimal one based on an information criterion. Pesaran and Shin suggested that the maximum lag order of the annual series data be chosen as 2 . The Formula (1) can be decomposed into a one-to-one corresponding conditional error correction (CEC) model as shown in Formula (2). PSS indicated that the CEC model is consistent with the CEC model obtained by the decomposition of vector autoregressive (VAR) model.

$$
\Delta y_{t}=a_{0}+a_{1} t-\psi(1) y_{t-1}+\sum_{j=1}^{k} \beta_{j}(1) x_{j, t-1}+\left(\tilde{\psi}^{*}(L) \Delta y_{t-1}+\sum_{j=1}^{k} \tilde{\beta}_{j}(L) \Delta x_{j, t-1}\right)+\sum_{j=1}^{k} \beta_{j}(L) \Delta x_{j, t}+\varepsilon_{t}
$$

The ARDL boundary cointegration test converts the cointegration test into a joint significance test (an $\mathrm{F}$ test or a Wald test) for the first-order lagged variables in the CEC model. PSS determined upper and lower thresholds for cases involving different numbers of independent variables, different significance levels, and the inclusion or exclusion of the intercept term and the time trend term. The upper threshold is obtained by assuming that all variables are series of first-order integration, and the lower threshold is obtained by assuming that all variables are series of zero-order integration. The calculated $\mathrm{F}$ value is compared with the thresholds provided by PSS. If the F statistic is less than the lower threshold, the null hypothesis is accepted and there is no long-term cointegration relationship between the variables. If it is greater than the upper threshold, there is a long-term cointegration between the variables; when it is between the upper and lower thresholds, the determination is based on the order of integration of the series.

In this paper, the maximum lag order of the independent variables and the dependent variables is set to $\leq 2$. The optimal lag order is determined according to the Akaike information criterion (AIC). The optimal ARDL model is obtained separately for three settings: without constant term or trend term, with constant term, and with constant term and trend term. Then, indicators such as the significance of the independent variables and the self-correlation of the residual sequence are used to select the optimal model corresponding to each cointegration relationship from among the three optimal models. The results indicate the following three situations: (1) the optimal model for describing the relationship between economic growth and $\mathrm{CO}_{2}$ emissions in Denmark is the ARDL $(2,0)$ model with the constant term and trend term, as shown in Formula (3).(2)the optimal model for describing the relationship between energy consumption and economic growth in Denmark is the ARDL $(2,0)$ model with the constant term and trend term, as shown in Formula (4). (3)the optimal model for describing the relationship between energy production and economic growth is the ARDL $(2,2)$ model with the constant term and trend term, as shown in Formula (5).

$$
\begin{aligned}
& \ln G D P_{t}=1.048133 \ln G D P_{t-1}-0.287512 \ln G D P_{t-2}+0.07598 \operatorname{lnCO} O_{t} \\
& +5.414167+0.004942 @ \text { trend } \\
& \operatorname{lnGDP_{t}}=0.84447 \ln G D P_{t-1}-0.225447 \ln G D P_{t-2}+0.123682 \text { lnconsuption }_{t} \\
& \text { +7.928744+0.006047@trend } \\
& \operatorname{lnGDP_{t}}=0.814852 \ln G D P_{t-1}-0.246555 \ln G D P_{t-2}+0.1275 \text { lnproduction }_{t} \\
& -0.027768 \text { lnproduction }_{t-1}-0.06023 \text { lnproduction }_{t-2}+10.60363 \\
& \text { +0.007508@trend }
\end{aligned}
$$

Assuming that the long-term equilibrium relationship contains a trend term, the boundary cointegration test is performed based on the obtained ARDL models. The test results are shown in Table 2. There is no long-term cointegration relationship among the economic growth and $\mathrm{CO}_{2}$ emissions sequences. Both energy consumption 
and production are cointegrated with economic growth at the significance levels of $1 \%$ and $5 \%$, respectively. Based on the ARDL models, the long-term equilibrium relationships between the variables are estimated; the results are shown in Table 3. It is found that with a $1 \%$ increase in energy consumption, economic growth increased by $0.324644 \%$, and with a $1 \%$ increase in energy production, the economic growth increased by $0.091505 \%$.

Table 2. Boundary cointegration test results

\begin{tabular}{ccc}
\hline & F value & Lower threshold \\
\hline Energy consumption and economic growth & 6.873516 & $6.73(1 \%)$ \\
Energy production and economic growth & 5.287816 & $5.15(5 \%)$ \\
Economic growth and $\mathrm{CO}_{2}$ emissions & 2.813033 & $4.05(10 \%)$ \\
\hline
\end{tabular}

Table 3. Long-term equilibrium relationships

\begin{tabular}{cccccc}
\hline & Variable & Coefficient & Std. Error & t-Statistic & Prob. \\
\hline Energy consumption and & Inconsumption & 0.324644 & 0.063509 & 5.111813 & 0.0000 \\
economic growth & & 0.015874 & 0.000839 & 18.91232 & 0.0000 \\
\hline Energy production and & Inproduction & 0.091505 & 0.016012 & 5.714878 & 0.0000 \\
economic growth & & 0.017392 & 0.001568 & 11.09109 & 0.0000 \\
\hline
\end{tabular}

\subsection{Error Correction Model}

According to Granger's representation theorem, an error correction model can be established between variables with a cointegration relationship. Therefore, based on the ARDL models, the equilibrium relationships between economic growth and both energy consumption and production are obtained. The error correction model are established, and the results are shown in Table 4. The coefficients of the error correction term of both models are significantly negative, and not less than -1 , which meets the requirements of the reverse adjustment mechanism, indicating that due to the short-term impact, the energy consumption and economic growth move out of long-term equilibrium but could return to long-term equilibrium at a speed of 0.29898. Similarly, the short-term deviated production of petroleum oil and gas resources and economic growth could return to long-term equilibrium at a speed of 0.431703 . The coefficients of the variables Alnconsumption and Slnproduction are positive at the $1 \%$ significance level, further illustrating that there are positive change relationships between Denmark's GDP and both the energy consumption and production.

Table 4. Error correction model

\begin{tabular}{cccccc}
\hline & Variable & Coefficient & Std. Error & t-Statistic & Prob. \\
\hline \multirow{2}{*}{ Energy consumption and } & $C$ & 6.229529 & 2.360050 & 2.639575 & 0.0136 \\
economic growth & & 0.230904 & 0.132780 & 1.738996 & 0.0934 \\
& & 0.182531 & 0.062923 & 2.900853 & 0.0073 \\
& & -0.298980 & 0.113479 & -2.634684 & 0.0138 \\
\hline Energy production and & & 10.61114 & 2.557027 & 4.149795 & 0.0004 \\
economic growth & & 0.246555 & 0.150741 & 1.635622 & 0.1150 \\
& & 0.127500 & 0.032996 & 3.864098 & 0.0007 \\
& & 0.060230 & 0.033071 & 1.821221 & 0.0811 \\
& & -0.431703 & 0.104137 & -4.145528 & 0.0004 \\
\hline
\end{tabular}




\subsection{Granger Causality Test}

Generally, there is at least one Granger causality between cointegrated variables. This paper conducted a Granger causality test with Eviews10. First, a VAR model was established, setting the maximum lag order to no more than 4. According to the different minimum information criteria of VAR models, namely, AIC, Schwarz information criterion (SC), final prediction error (FPE), and Hannan-Quinn information criterion (HQ), the optimal lag order for the energy consumption and economic growth model is 1 and the optimal lag order for the energy production and economic growth model is 2 . When the Granger causality test was performed, the lag order of the model was reduced by 1 accordingly, and the test results are shown in Table 5 . The null hypothesis that "Inconsumption does not Granger-cause $\ln G D P$ " is acceptable, but the null hypothesis that "InGDP does not Granger-cause lnconsumption" is rejected; that is, there is one-way causality from economic growth to energy consumption. Similarly, there is a one-way causality from economic growth to energy production. In other words, economic growth Granger-causes the energy consumption and production.

Table 5. Granger causality test results

\begin{tabular}{ccc}
\hline Null Hypothesis & F Statistic & Prob. \\
\hline Inconsumption does not Granger-cause InGDP & 1.04622 & 0.3148 \\
InGDP does not Granger-cause Inconsumption & 6.43076 & 0.0169 \\
Inproduction does not Granger-cause InGDP & 0.24570 & 0.7840 \\
InGDP does not Granger-cause Inproduction & 4.33261 & 0.0238 \\
\hline
\end{tabular}

\section{Discussion}

Based on the above empirical analysis results, there are cointegration relationships between Denmark's economic growth and both the energy consumption and production. Economic growth Granger-causes the energy consumption and production, which is in line with the actual situation of energy economic development in Denmark. To some extent, it is also related to the green energy policy that has long been advocated by Denmark. This paper further discusses this in consideration of Denmark's energy policy and the current status of its energy economy.

\subsection{Equilibrium Relationships between GDP and Both Energy Consumption and Production}

The empirical analysis shows that there is a long-term cointegration relationship between economic growth and energy consumption at the significance level of $1 \%$. At the significance level of $5 \%$, there are cointegration relationships between economic growth and both the energy consumption and production. Statistically, the cointegration relationship between economic growth and energy consumption is more significant.

The long-term equilibrium between GDP and energy consumption and between GDP and energy production all contain a trend term. Economic growth has a trend, but the coefficient of the trend term in the two models is very small, indicating that the effect of the economic growth trend is not very significant. There are positive long-term equilibrium relationships between economic growth and both the energy consumption and production, but the coefficient of oil and gas consumption is much larger, indicating that the increase in oil and gas consumption could promote the economy in the long run and that the promoting effect of consumption could be more significant.

\subsection{Adjustments of the Equilibrium Relationships between GDP and both the Energy Consumption and Production}

The error correction model reflects the state of short-term adjustment when the variables deviate from the long-term equilibrium relationship. The comparisons of the error correction models for the energy consumption and production and GDP show that there are positive relationships between the change in GDP and both the change in oil and gas consumption and production. The coefficient of change in oil and gas consumption is relatively large, and change in oil and gas production for the preceding year has a small impact on the corresponding economic change. In the short term, changes in oil and gas consumption and production could lead to same-direction changes in the economy; to a similar extent, change in the GDP for the preceding year has a positive effect on current change in the two models. The term reflects the speed of adjustment to the equilibrium when deviation from the equilibrium occurs. The comparison between the two models shows that the speed of adjustment for the energy production and economic growth is much faster when they move out of 
the equilibrium relationship.

\subsection{Causal Relationships between GDP and both the Energy Consumption and Production}

The Granger causality test results show that at the $5 \%$ significance level, economic growth Granger-causes the energy consumption and production, and the one-way causality from economy to energy consumption is more significant. Economic growth has driven energy demand, including energy consumption and energy production. Economic changes are conducive to explaining the changes of energy consumption and production in the future, while the increase in energy consumption and production cannot be interpreted as an engine to propel economic growth. Reduction in energy consumption and production does not lead to a reduction in GDP, which also confirms the fact that Denmark promotes energy conservation but still maintains stable economic growth.

\subsection{No Cointegration Relationship between Consumption of Oil and Gas Resources, Economic growth and $\mathrm{CO}_{2}$ Emissions}

There is no co-integration relationship between economic growth and greenhouse gas emissions in Denmark, which indicates that Denmark has successfully realized the basic decoupling between economic growth and carbon emissions, and there is no co-integration relationship between consumption of oil and gas resources and $\mathrm{CO}_{2}$ emissions, indicating that there is no long-term relationship between consumption of oil and gas resources and contribution of $\mathrm{CO}_{2}$ emissions in Denmark. This is in line with the fact that Denmark's energy consumption is decreasing year by year. Its energy consumption is at the lowest level in the world, and the ratio of energy consumption to national income is also the smallest among OECD member countries. Denmark can maintain high-efficiency economic growth while energy consumption and carbon emissions decline simultaneously, which is closely related to its energy consumption restructuring and its energy policy.

Denmark has formulated ambitious renewable energy development goals and implemented a sound, positive and cost-effective energy policy in terms of energy transformation and structural adjustment policies. Denmark, for example, produces oil and gas, but invests its oil and gas revenues in green energy, successfully realizing its green transformation. Denmark's decoupling of economic growth from carbon emissions is largely due to three major contributions: renewable energy generation, improved plant efficiency and cogeneration. Although Denmark has virtually no hydropower resources, it has succeeded in becoming a global leader in renewable energy generation, with more than $25 \%$ of its final energy consumption coming from renewable sources. From the point of view of power supply, Denmark currently accounts for nearly $50 \%$ of the domestic electricity generation from renewable energy, mainly from wind power. The new renewable energy technology has fundamentally changed the Danish energy system and power net. According to a recent study, energy efficiency gains over the past decade have increased Danish manufacturing cost competitiveness by $9 \%$.

\subsection{Discussion and Analysis}

The results of this series of cointegration tests were all based on the sample data from 1984 to 2016. During this period, there were long-term equilibrium relationships between Denmark's economic growth and its energy consumption and production, indicating that energy resources play a more important role in promoting economic growth. There was one-way causality from economic growth to the energy consumption and production, but no two-way causality. This finding may be because Denmark's energy transition strategy initially began to show effects in the 1980s. For example, Denmark introduced the oil tax in 1977 and the coal tax in 1982. Based on the characteristics of the tax itself, the implementation conditions, and government policy objectives, different taxes were introduced at different times, and the environmental tax was gradually promoted. With the implementation of these policy measures, the dependence of its economic growth on energy resources was gradually reduced. However, the economic growth stimulated the demand for energy consumption and production. The growth in energy consumption demand promoted the development of the energy transition. For instance, Denmark's experience in oil exploration in many dangerous conditions in the past has become the major driver of Denmark's offshore wind industry. Its green transformation was also based on its rich experience in the maritime construction industry. The demand for energy production was mainly based on the need to adjust the energy structure, and the income from its oil and natural gas and the main efforts were invested into green energy, which means that Denmark still need to maintain the production of its oilfield to ensure that the income from the oil and gas business would be invested in renewable energy. These policy measures and actual needs have led to a successful green transformation.

Other key factors for Denmark's successful energy transition, which propelled its economy, were promoted after the 1980s and included the development of green technologies, the promotion of various energy-saving technologies and measures, and the improvement of public facilities to guide citizens' green lives. Denmark not only used taxation and construction of public facilities and other methods to inhibit the use of fossil fuels at the 
source but also developed green energy technologies that both found alternatives to fossil energy and brought technical output to Denmark so that the reduction in its energy consumption and production would not negatively impact its economy.

Denmark has indeed made recognized achievements in pursuing the green economy, but its petroleum consumption still accounts for a large proportion. In addition, renewable natural gas, such as biomass, has been developing rapidly, and a portion of natural gas will become renewable energy. However, the renewable energy cannot replace natural gas in the fields of heating, vehicles, and ships, and natural gas will continue to play an irreplaceable role. Petroleum resources are still an important support for Denmark's industrial development. Economic changes can explain energy use and survival to a certain extent.

Denmark's energy development model shows that formulating effective energy development policies, especially renewable energy development and utilization policies, improving energy efficiency, supporting technological innovation and industrial development, can maintain significant economic growth while maintaining a high standard of living, achieving a high level of energy supply security, while reducing less dependence on fossil fuels and mitigation of climate change. Throughout the overall view of Danish energy planning, the focus is on integration, such as thermal and power production, to bring into play the synergy between tax policies and supporting policy frameworks for renewable energy development. Denmark's policy orientation, legal system, and innovative technologies are of important significance as a reference for China's social construction.

\section{Conclusion and Policy Implications}

This paper used the ARDL boundary cointegration test to test and analyze the cointegration relationships between Denmark's economic growth and energy consumption and production, and determine no co-integration relationship between carbon emissions and economic growth. The conclusions are as follows:

(1) There are cointegration relationships between Denmark's economic growth and both energy consumption and production. By comparing the long-term equilibrium relationships, it is found that energy production and consumption have positive effects on the economy in the long run. However, the change in the energy production has a relatively small effect on the economy.

(2) An error correction model is established to analyze the short-term dynamic relationship between the variables, and the results show that the energy consumption and production have a small effect on the economy in the short term. The comparison of error correction models shows that the adjustment speed is slower when the energy consumption and the economic growth move out of the equilibrium relationship.

(3) The Granger causality test finds that there is a one-way causality from Denmark's GDP to the energy consumption and production. Economic changes are conducive to explaining the changes of energy consumption and production in the future. Denmark's rapid economic growth will lead to an increase in its oil and gas consumption and production. The increase is consistent with Denmark's practices of its energy economy.

(4) Analysis of the relationships between the empirical results and Denmark's economic development and policy measures shows that the economic growth drives the demand for its energy consumption and production. The growth of energy consumption demand promotes the adjustment of its energy structure. The demand for energy production is due to its green transformation, which requires oil and gas production income. In this series of processes, Denmark not only inhibits the use of fossil fuels through taxation and construction of public facilities but also advocates green energy development technologies, energy conservation, and emission reduction measures to promote green transformation.

\section{Acknowledgments}

This work was conducted under the National Key Research and Development Program of China (NO2016YFC1402701), and supported by the China Geological Survey project for Study on the Deployment of Marine Geological Survey (Grant No. DD20160158) and the Chinese Polar Environment Comprehensive Investigation\& Assessment Programmes (CHINARE2018, JD0619002,JD0619003, JDKC0318001).

\section{References}

Che, M. et al. (2017). The Enlightenment of European and Danish Energy Transformation on China's Natural Gas Development. Sino-Global Energy, 22(9), 13-17.

Chen, H. M., Ning, Y. C., \& Qi, X. H. (2012). On the Relationship between Economic Growth, Energy Consumption and $\mathrm{CO}_{2}$ Emission in China. Science and Technology Management Research, 32(10), 198-202.

Chen, J. H. (2013). The Chinese interpretation of "The Danish fairy tale". Shanghai Economy, (5), 28-29. 
Chen, Z. M. (2015). Research on the Relationship between Energy Consumption, Carbon Dioxide Emission and Economic Growth in China Based on ARDL Model. China Circulation Economy, 31(14), 14-16.

Fan, L., Xu, X. F., Zhang, R. M. (2011). What is behind the Zero Energy Consumption Growth of Denmark during the Last 30 Years. World Environment, (3), 64-66.

Johansen, S. (1988). Statistical analysis of cointegration vectors. Journal of Economic Dynamics \& Control, 12(2), 231-254. https://doi.org/10.1016/0165-1889(88)90041-3

Li, Y. (2011). The Danish Environmental Tax System and Its Enlightenment to China. Economic Forum, (10), 191-194.

Li, Y. H. (2014). Measure the causality between economic growth and power consumption by the ARDL method. Digest of Management Science, (4), 77-78.

Liu, B. C. (2014). Denmark's “zero carbon economy”. Chinese and foreign corporate culture, (3).

Narayan, P. K. (2004). Reformulating Critical Values for the Bounds F- statistics Approach to Cointegration: An Application to the Tourism Demand Model for Fiji.

Pesaran, M. H., \& Shin, Y. (1999). An Autoregressive Distributed Lag Modeling Approach to Cointegration Analysis, Chapter 11. In S. Storm (Ed.), Econometrics and Economic Theory in the 20th Century: the Ragnar Frisch Centenniao Symposium. Cambridge University Press, Cambridge.

Pesaran, M. H., \& Smith, R. P. (1998). Structural Analysis of Cointegrating VARs. Journal of Economic Survey, 12(5), 471-505. https://doi.org/10.1111/1467-6419.00065

Pesaran, M. H., Shin, Y., \& Smith, R. J. (2001). Bounds testing approaches to the analysis of level relationships. Journal of Applied Econometrics, 16(3), 289-326. https://doi.org/10.1002/jae.616

Wang, J. L., \& Zhao, J. J. (2008). Causality Measurement and Analysis of Energy Consumption and Economic Growth: Based on China Sample. Industrial technology economy, 27(1), 86-91.

Wang, S. S. et al. (2011). Research on the Relationship between Energy Consumption and Economic Growth of Three Industties Based on ARDL. Soft Science, 25(5), 74-76.

Yang, H. Y. (2000). Coal Consumption and Economic Growth in Taiwan. Energy Sources, 22, 109-115. https://doi.org/10.1080/00908310050014081

Ye, F. (2005). Denmark's experience in solving energy problems. Global Science, Technology and Economy Outlook, (2), 53-55.

Yu, E., \& Choi, J. (1985). The causal relationship between energy and GNP, an international comparison. Journal of Energy and Development, 10, 249-275.

Zhai, S. Y., \& Wang, Z. (2013). Research on the relationship between carbon emission, energy consumption and economic growth in the Yangtze River Delta based on ARDL model. Resources and Environment in the Yangtze Basin, 22(1), 94-103.

Zhang, N. (2007). Looking at the characteristics of low carbon economy from the Danish "energy model". Global Science, Technology and Economy Outlook, 22(12), 50-51.

Zhu, T. B. (2008). Analysis of the late development path in Denmark. European Research, (4), 78-88.

\section{Copyrights}

Copyright for this article is retained by the author(s), with first publication rights granted to the journal.

This is an open-access article distributed under the terms and conditions of the Creative Commons Attribution license (http://creativecommons.org/licenses/by/4.0/). 